\title{
Methodological Tools for Exploring Novel Biopharmaceutical Approaches to the Metabolic Syndrome and Related Disorders
}

\author{
A Commentary on: Translational Research Methods in Diabetes, Obesity, \\ and Nonalcoholic Fatty Liver Disease. A Focus on Early Phase Clinical \\ Drug Development, Second Edition
}

Amedeo Lonardo · Enrica Baldelli

Received: January 13, 2020 / Published online: March 7, 2020

(C) The Author(s) 2020

Keywords: Drug therapy; Metabolic syndrome; NAFLD

\section{DEFINITIONS OF METABOLIC SYNDROME AND NAFLD}

The term metabolic syndrome (MetS) defines a cluster of cardio-metabolic risk factors that predispose a person to developing organ failure and some types of cancer [1]. Moreover, each individual component of the MetS tends to predict the future incidence of further features of the syndrome [1], and the presence of the MetS amplifies the risk of incident type 2 diabetes (T2D) and cardiovascular disease [2].

Nonalcoholic fatty liver disease (NAFLD) encompasses a spectrum of alcohol-like liver histology changes, such as simple steatosis (also named NAFL), nonalcoholic steatohepatitis (NASH), NASH-cirrhosis and NASH-

Enhanced Digital Features To view enhanced digital features for this article go to https://doi.org/10.6084/ m9.figshare.11890377.

A. Lonardo $(\square)$

Azienda Ospedaliero-Universitaria di Modena,

Modena, Italy

e-mail: a.lonardo@libero.it;

lonardo.amedeo@aou.mo.it

E. Baldelli

Università degli Studi di Modena e Reggio Emilia,

Modena, Italy hepatocellular carcinoma (NASH-HCC), which occur in the absence of significant alcohol consumption and of other competing etiologies of chronic liver disease [3]. At odds with one of its earliest definitions [4], NAFLD is currently not recognized as a feature of the MetS despite there being strong evidence that supports a strong mutual and bi-directional association of NAFLD with the MetS $[5,6]$. NAFLD is a systemic disorder with several hepatic and extrahepatic manifestations $[7,8]$, and it follows a variable course that is chiefly dictated by liver histology. For example, the development of NAFLD-cirrhosis is associated with hepatic complications, whereas the presence of hepatic fibrosis is more closely associated with extrahepatic conditions [7].

\section{BURDEN OF DIABETES, OBESITY AND NAFLD AND THEIR ASSOCIATION}

The epidemiological burden of the MetS and its components is substantial. T2D, whose future prevalence is projected to be on the rise, currently affects more than 400 million people worldwide and is a major determinant of blindness, non-traumatic amputations of lower limbs, chronic kidney disease and cardiovascular morbidity, accounting for an overall expenditure of $>\$ 11,500$ per individual patient [9]. 
T2D is often associated with obesity (hence the name "diabesity" given to this dangerous and common combination) [3]. As a result of a complex interaction among genetical, sociocultural, economical, psycho-behavioral and pharmacological determinants [10], the prevalence of obesity has increased worldwide, particularly among women, racial/ethnic groups and individuals with lower levels of education/ income $[11,12]$. Compared to individuals who are of average weight, those who are obese carry an increased annual financial burden associated with healthcare expenses (36\%) and drugs (77\%) [12]. NAFLD, which is common in individuals with diabesity [13-15], occurs in one in four people in the world and is the most rapidly growing chronic liver disease, accounting, over time, for a substantial increase in clinical burden and healthcare expenditures $[16,17]$.

The trajectories in the epidemiology of vascular disease and T2D are dissociated from each other; for example, the mortality owing to circulatory diseases has continuously declined since 1945, while the prevalence of diabesity has dramatically escalated during the same period of time [18]. This justifies making every effort to try to halt the diabesity epidemic of which NAFLD is both a cause and a consequence $[19,20]$. Moreover, given that diabesity and nephro-cardiovascular diseases are closely associated to each other (mirroring shared pathophysiological pathways and risk factors), a strong case has been made in favor of a close collaboration and more effective integration in the field of cardio-metabolic research [21].

A strict metabolic control may alter the natural course of the MetS [22]. This notion, together with the epidemiological data summarized above, fully justifies a major research effort to develop and evaluate innovative pharmacological treatment options of the individual constitutive features of the MetS [2, 23, 24]. Some of these features may also benefit from metabolic surgery [25-28].

\section{TRANSLATIONAL RESEARCH METHODS IN DIABETES, OBESITY, AND NONALCOHOLIC FATTY LIVER DISEASE. A FOCUS ON EARLY PHASE CLINICAL DRUG}

Although provocatively defined by E. Ferrannini in 2007 as "...a solution in search of a problem" [29], the MetS is now undisputedly deemed to be a major clinical and public health concern worldwide. The association of various components of the MetS was first described between the 1920s and 1940s [30]. However, the term "metabolic syndrome" was used for the first time in 1952 [31]. In the 1960s, Avogaro and Crepaldi referred to the MetS as the "plurimetabolic syndrome", and Randle illustrated the interactions between the metabolism of lipids and glucose [30]. In 1977, Haller included "hepatic steatosis" (i.e. NAFLD or NAFL) as a feature of the MetS [4]. However, what we now call "NASH" was first reported by Thaler in 1962, and what would now be called "NASH-cirrhosis" was reported in 1979 by Itoh and in 1980 by Ludwig who coined the name "nonalcoholic steatohepatitis" [32].

Given this historical background and prompted by the success gained by the first edition, this second edition of Translational Research Methods in Diabetes, Obesity, and Nonalcoholic Fatty Liver Disease. A Focus on Early Phase Clinical Drug Development bestows much more importance to metabolic liver disease spanning the entire spectrum of NAFLD and NASH. Therefore, the present edition is a useful guide for those researchers who are interested in the study of novel drugs to manage certain selected individual components of the MetS, such as diabesity and NASH.

To whom should this book be recommended reading? We believe that academic and clinical scientists (along with their students and fellows) who are involved in research on metabolic disorders may find this book quite interesting and thought-provoking reading. However, persons involved in basic science and, in particular, in the clinical bio-pharmaceutical arena aimed at researching and developing novel drugs for diabesity and related disorders represent the 
ideal recipients of the messages conveyed by this book. In addition, those who participate in the assessment of novel drugs for the treatment of the MetS, i.e. the so-called "trialists," may also find reading this book very interesting.

The textbook consists of two sections. The first part, entitled "Review of Clinical Investigative Methods," is a comprehensive analysis of the clinical research tools to be used in earlyphase clinical drug development for the treatment of T2D and NAFLD/NASH and focuses on the pros and cons of established and emerging clinical research techniques [33]. The topics discussed include the quantification of insulin action in humans; assessment of the function of islet $\alpha$ - and $\beta$-cells; the pharmaco-kinetic-dynamic assessment of novel and biosimilar insulins and measurement of energy expenditure; quantification of appetite and satiety; noninvasive quantitative magnetic resonance imaging and spectroscopic biomarkers in NAFLD and other cardiometabolic conditions featuring the deposition of ectopic fat; the structural and functional imaging of muscle, heart, endocrine pancreas and kidneys; the role of positron emission tomography (PET) and computed tomography (CT) measurement of brown fat thermal activation (a key tool for developing novel drug therapeutics for diabesity); isotopic tracers for the measurement of metabolic fluxes; the utility of invasive and non-invasive cardiovascular research methodologies in drug development for diabesity and NAFLD/NASH; and potential role of omics technology in early phase development of drugs. A chapter of particular value within this section is entitled "Role of Tissue Biopsy in Drug Development for Nonalcoholic Fatty Liver Disease and Other Metabolic Disorders." This chapter was written by Andrew J. Krentz and Pierre Bedossa who, while having quite different working perspectives, are both well placed to provide the reader with a novel overview of an important but often neglected topic.

The second part of the textbook, "Preclinical Drug Development and Transitioning to Clinical Studies," focuses on the transition to clinical studies. Importantly, the concepts of personalized and precision medicine are widely discussed throughout the text [33]. This section has chapters dedicated to animal models of diabesity and NASH; going further with hemoglobin A1c in the development of novel drugs for diabetes mellitus; extending beyond quantitative approaches in translational cardio-metabolic research; transitioning from preclinical to clinical drug development; regulatory considerations for early clinical development of drugs for diabesity, NASH and related cardio-metabolic disorders; and early phase metabolic research with reference to special populations. Among these, we highlight the chapter entitled "Emerging Circulating Biomarkers for The Diagnosis and Assessment of Treatment Responses in Patients with Hepatic Fat Accumulation, Nash and Liver Fibrosis." This chapter was contributed by F. Bril, a leading authority on NAFLD associated with T2D, and colleagues.

The chief features and definite points of strength of this textbook are the emphasis on quantitative assessment (e.g. insulin action, energy expenditure, appetite and satiety and others); role of imaging techniques (e.g. magnetic resonance imaging and spectroscopy, PET and CT); evaluation of functions (e.g. metabolic fluxes); and histological assessment of metabolic organs (e.g. liver, muscle and adipose tissue).

The limitations of this textbook include a failure to provide an integrated view of the fullblown metabolic syndrome (e.g. arterial hypertension and dyslidpidemia are, notably, two missing areas) as well as to depict the natural history of diseases compared to which any drug treatment must be evaluated. Finally, attention should be paid to disease models that avoid manipulation of living animals. However, these comments are meant to be constructive and friendly suggestions for the (eagerly awaited) next editions rather than true criticisms.

\section{ACKNOWLEDGMENTS}

Funding. No funding or sponsorship was received for this study or publication of this article.

Authorship. All named authors meet the International Committee of Medical Journal 
Editors (ICMJE) criteria for authorship for this article, take responsibility for the integrity of the work as a whole, and have given their approval for this version to be published.

Disclosures. Amedeo Lonardo and Enrica Baldelli have nothing to disclose.

Compliance with Ethics Guidelines. This article is based on previously conducted studies and does not contain any studies with human participants or animals performed by any of the authors.

Data Availability. Data sharing is not applicable to this article as no datasets were generated or analyzed during the current study.

Open Access. This article is licensed under a Creative Commons Attribution-NonCommercial 4.0 International License, which permits any noncommercial use, sharing, adaptation, distribution and reproduction in any medium or format, as long as you give appropriate credit to the original author(s) and the source, provide a link to the Creative Commons licence, and indicate if changes were made. The images or other third party material in this article are included in the article's Creative Commons licence, unless indicated otherwise in a credit line to the material. If material is not included in the article's Creative Commons licence and your intended use is not permitted by statutory regulation or exceeds the permitted use, you will need to obtain permission directly from the copyright holder. To view a copy of this licence, visit http://creativecommons.org/ licenses/by-nc/4.0/.

\section{REFERENCES}

1. Lonardo A, Ballestri S, Marchesini G, Angulo P, Loria P. Nonalcoholic fatty liver disease: a precursor of the metabolic syndrome. Dig Liver Dis. 2015;47: 181-90.

2. Bahadori E, Farjami Z, Rezayi M, et al. Recent advances in nanotechnology for the treatment of metabolic syndrome. Diabetes Metab Syndr. 2019;13:1561-8.
3. Italian Association for the Study of the Liver (AISF). AISF position paper on nonalcoholic fatty liver disease (NAFLD): updates and future directions. Dig Liver Dis. 2017;49:471-483.

4. Haller H. Epidemiology and associated risk factors of hyperlipoproteinemia. Z Gesamte Inn Med. 1977;32:124-8.

5. Lonardo A, Nascimbeni F, Mantovani A, Targher G. Hypertension, diabetes, atherosclerosis and NASH: cause or consequence? J Hepatol. 2018;68:335-52.

6. Yki-Järvinen H. Non-alcoholic fatty liver disease as a cause and a consequence of metabolic syndrome. Lancet Diabetes Endocrinol. 2014;2:901-10.

7. Vilar-Gomez E, Calzadilla-Bertot L, Wai-Sun Wong $\mathrm{V}$, et al. Fibrosis severity as a determinant of causespecific mortality in patients with advanced nonalcoholic fatty liver disease: a multi-national cohort study. Gastroenterology. 2018;155:443-57.

8. Ballestri S, Mantovani A, Nascimbeni F, Lugari S, Lonardo A. Extra-hepatic manifestations and complications of nonalcoholic fatty liver disease. Future Med Chem. 2019;11:2171-92.

9. Rodriguez-Gutierrez R, Gonzalez-Gonzalez JG, Zuñiga-Hernandez JA, McCoy RG. Benefits and harms of intensive glycemic control in patients with type 2 diabetes. BMJ. 2019;367:15887.

10. Skelton JA, Irby MB, Grzywacz JG, Miller G. Etiologies of obesity in children: nature and nurture. Pediatr Clin North Am. 2011;58:1333-54.

11. Arroyo-Johnson C, Mincey KD. Obesity epidemiology worldwide. Gastroenterol Clin North Am. 2016;45:571-9.

12. Apovian CM. Obesity: definition, comorbidities, causes, and burden. Am J Manag Care. 2016;22[7 Suppl]:s176-85.

13. Non-alcoholic Fatty Liver Disease Study Group, Lonardo A, Bellentani S, et al. Epidemiological modifiers of non-alcoholic fatty liver disease: focus on high-risk groups. Dig Liver Dis. 2015;47: 997-1006.

14. Lonardo A, Lugari S, Ballestri S, Nascimbeni F, Baldelli E, Maurantonio M. A round trip from nonalcoholic fatty liver disease to diabetes: molecular targets to the rescue? Acta Diabetol. 2019;56: 385-96.

15. Lonardo A, Mantovani A, Lugari S, Targher G. Epidemiology and pathophysiology of the association between nafld and metabolically healthy or metabolically unhealthy obesity. Ann Hepatol. (in press). 
16. Nguyen AL, Park H, Nguyen P, Sheen E, Kim YA, Nguyen MH. Rising inpatient encounters and economic burden for patients with nonalcoholic fatty liver disease in the USA. Dig Dis Sci. 2019;64: 698-707.

17. Younossi ZM, Tampi RP, Racila A, et al. Economic and clinical burden of nonalcoholic steatohepatitis in patients with type 2 diabetes in the United States. Diabetes Care. 2020;3(2):283-89.

18. Taylor D. Vascular disease and type 2 diabetes: the science policy case for early cardiometabolic intervention. Cardiovasc Endocrinol Metab. 2019;8: 49-50.

19. Ballestri S, Zona S, Targher G, et al. Nonalcoholic fatty liver disease is associated with an almost twofold increased risk of incident type 2 diabetes and metabolic syndrome. Evidence from a systematic review and meta-analysis. J Gastroenterol Hepatol. 2016;31:936-44.

20. Ballestri S, Nascimbeni F, Romagnoli D, Lonardo A. The independent predictors of non-alcoholic steatohepatitis and its individual histological features: insulin resistance, serum uric acid, metabolic syndrome, alanine aminotransferase and serum total cholesterol are a clue to pathogenesis and candidate targets for treatment. Hepatol Res. 2016;46:1074-87.

21. Krentz AJ, Jacob S. Cardiometabolic medicine: time to recognize a new clinical specialty? Cardiovasc Endocrinol Metab. 2019;8(2):47-8.

22. Reaven PD, Emanuele NV, Wiitala WL, et al. Intensive glucose control in patients with type 2 diabetes-15-year follow-up. N Engl J Med. 2019;380: 2215-24.

23. Sookoian S, Pirola CJ. Review article: shared disease mechanisms between non-alcoholic fatty liver disease and metabolic syndrome-translating knowledge from systems biology to the bedside. Aliment Pharmacol Ther. 2019;49:516-27.

24. Lazarević S, Đanić M, Goločorbin-Kon S, Al-Salami H, Mikov M. Semisynthetic bile acids: a new therapeutic option for metabolic syndrome. Pharmacol Res. 2019;146:104333.

25. Nudel J, Sanchez VM. Surgical management of obesity. Metabolism. 2019;92:206-16.

26. Sinclair P, Brennan DJ, le Roux CW. Gut adaptation after metabolic surgery and its influences on the brain, liver and cancer. Nat Rev Gastroenterol Hepatol. 2018;15:606-24.

27. Salminen P, Helmiö M, Ovaska J, et al. Effect of laparoscopic sleeve gastrectomy vs laparoscopic Roux-en-Y Gastric bypass on weight loss at 5 years among patients with morbid obesity: the SLEEVEPASS randomized clinical trial. JAMA. 2018;319: 241-54.

28. le Roux CW, Heneghan HM. Bariatric surgery for obesity. Med Clin North Am. 2018;102:165-82.

29. Ferrannini E. Metabolic syndrome: a solution in search of a problem. J Clin Endocrinol Metab. 2007;92:396-8.

30. Sarafidis PA, Nilsson PM. The metabolic syndrome: a glance at its history. J Hypertens. 2006;24:621-6.

31. Berardinelli W, Cordeiro JG, Albuquerque D. Couceiro A. [A new endocrine-metabolic syndrome probable related to total somatotropin hyperfunction]. Med Cir Farm. 1952;200:555-68.

32. Lonardo A, Loria P, Argo C, Caldwell S. Perspectives on cellular dysfunction in nonalcoholic steatohepatitis: a case of 'multiorganelle failure'? Proceedings of a virtual workshop on nonalcoholic steatohepatitis. Expert Rev Gastroenterol Hepatol 2011;5: 135-39.

33. Jerrold M, Olefsky JM. Foreword. In: Krentz AJ, Weyer C, Hompesch M, editors. Translational research methods in diabetes, obesity, and nonalcoholic fatty liver disease. A focus on early phase clinical drug development. 2nd edition. Cham: Springer International Publishing; 2019. p. v-vi 